\title{
A Novel Resident-as-Teacher Curriculum to Improve Residents' Integration Into the Clinic
}

\author{
Leslie A. Hoffman, PhD | David T. Furman Jr, DO | Zachry Waterson, DO | Brian Henriksen, PhD
}

PRiMER. 2019;3:9.

Published: 3/11/2019 | DOI: 10.22454/PRiMER.2019.394096

\section{Abstract}

Introduction: Graduate medical education depends on senior residents to facilitate peer education. Previous studies have described the benefits of resident-as-teacher (RaT) curricula; however, means of assessing these interventions have proven difficult. The purpose of this study was to provide meaningful evaluation of a novel RaT curriculum and scribing activity.

Methods: Didactic sessions on teaching skills were presented in July, 2017. First- and third-year residents then alternated scribing for each other for 4 weeks within the outpatient clinic to allow for near-peer educational exchange. Residents' attitudes toward teaching and perceptions of teaching abilities were assessed using preand postintervention surveys. Independent reviewers reviewed charts completed by PGY-1 residents during the scribing activity, and compared them to charts from the previous academic year.

Results: All first-year ( $n=12 ; 100 \%)$ and third-year $(n=10 ; 100 \%)$ residents participated in the study. After participating in the RaT curriculum, residents were more comfortable giving feedback to other residents and felt better prepared to teach and assess the effectiveness of their teaching. Although there was no significant difference in ratings between the 2016 and 2017 charts, reviewers noted that the 2017 charts contained fewer obvious omissions, and third-year residents felt the charts were completed in a timelier manner. Firstyear residents saw $16 \%$ more patients in 2017 than they had in 2016, which expedited integration into the clinic.

Conclusion: This innovative RaT curriculum with scribing activity improved residents' teaching and communication skills and provided first-year residents with a more efficient and meaningful orientation into the outpatient clinic.

\section{Introduction}

Resident physicians estimate that they spend up to $25 \%$ of their time teaching. ${ }^{1,2}$ Resident-as-teacher (RaT) curricula can improve residents' teaching skills, ${ }^{3,4}$ and the number of family medicine residency programs offering RaT curricula has increased from $52 \%$ in 2000 to $85 \%$ in $2014.5,6$ Despite the increase in RaT programs, meaningful evaluation of such programs has proven difficult. ${ }^{7}$ This study examined a novel RaT curriculum with near-peer scribing activity designed to orient first-year residents to the outpatient clinic and increase their familiarity with the electronic medical record (EMR).

Near-peer teaching benefits both teachers and learners. Near-peer teachers report increases in self-esteem, motivation, communication, and leadership skills, and enhanced understanding of the subject matter being taught. ${ }^{8}$ A shorter cognitive distance (ie, cognitive congruence) between near-peer teachers and learners allows the teacher to better understand learners' challenges and explain difficult concepts at an appropriate level. ${ }^{9,10}$ Under the 
guidance of a more experienced peer, learners operate in their zone of proximal development (ZPD), which allows them to achieve more than they might have working alone. ${ }^{11}$ Peers are also viewed as less threatening than experts, which creates a safe environment for learners to ask questions and make mistakes. ${ }^{9}$

The objectives of the RaT curriculum were to: (1) increase residents' confidence in their teaching abilities; (2) increase communication and build relationships among residents; and (3) expedite the orientation process for firstyear residents.

Evaluation of the RaT curriculum was guided by Kirkpatrick's 4 -level evaluation model. ${ }^{12}$ Level 1 assesses learners' reactions and satisfaction; level 2 assesses learning attributed to the curriculum; level 3 assesses application of knowledge or skills gained; and level 4 assesses the curriculum's impact in a larger context.

\section{Methods}

A RaT curriculum was introduced to all family medicine resident physicians in a single program, the Fort Wayne Medical Education Program ( $N=32$ ), in July 2017. The curriculum used didactic sessions to present "Resident Teaching Skills,"13 and "One-Minute Preceptor,"14 after which, first-year (PGY-1) and third-year (PGY-3) residents were paired up for a 4-week scribing activity. During the first 2 weeks, first-year residents acted as scribes for senior residents during outpatient encounters. Observing the PGY-3 residents provided a model for the PGY-1 residents to follow and build upon as they operated within their ZPD. ${ }^{11}$ During the second 2 weeks the roles were reversed, and PGY-1 residents led the patient encounter while PGY-3 residents acted as scribes. Throughout the activity, senior residents provided feedback to first-year residents on charting, interviewing, and physical exam skills when opportunities presented between patients, as well as at the end of the clinic day.

Pre- and postintervention surveys were administered to solicit resident feedback and determine the effect of the RaT curriculum on residents' attitudes toward teaching and their level of confidence in the educator role. The survey was developed by the authors and included 11 items that used a 4-point Likert scale (4=strongly agree; $1=$ strongly disagree) to elicit responses.

After the scribing activity, 24 charts completed by PGY-1 residents were randomly selected for review by one of three independent reviewers (ie, attending physicians in the clinic). These 24 charts represented approximately $8 \%$ of the total number of charts completed by PGY-1 residents during the study period. For comparison, reviewers also examined 24 charts from the previous year's (2016) PGY-1 residents, who had not participated in the scribing activity. Reviewers utilized the clinic's standard chart review form (available on request) to detect errors and omissions. The Lutheran Hospital Institutional Review Board deemed the study protocol exempt.

\section{Results}

All PGY-1 ( $n=12 ; 100 \%)$ and PGY-3 ( $n=10 ; 100 \%)$ residents participated in the RaT curriculum and scribing activity. Open-ended comments revealed that first-year residents thought the scribing activity was a good way to learn the EMR and helped them feel more integrated into the clinic. First-year residents also felt they had developed relationships with the senior residents.

Survey results are presented in Table 1. Wilcoxon signed-rank tests found that after participating in the RaT curriculum, all residents felt more confident in their ability to assess learners' needs $(z=2.55 ; P=.011)$ and assess the effectiveness of their teaching $(z=2.50 ; P=.013)$, were more comfortable giving feedback to other residents $(z=2.13$; $P=.033)$, and felt better prepared to teach other residents and/or medical students in the clinic $(z=2.45 ; P=.014)$. Third-year residents also felt more comfortable asking questions of other residents $(z=2.34 ; P=.025)$.

An independent samples t-test showed no difference in evaluator ratings between the 2016 and 2017 PGY-1 charts $(P=0.375)$. However, evaluators commented that 2017 charts contained fewer gross errors than 2016 charts.

Additionally, there was a $16 \%$ increase in the number of patients seen in the first month by the 2017 PGY-1 residents as compared to the 2016 PGY- 1 residents. 


\section{Conclusion}

Overall, the novel RaT curriculum achieved its objectives, based on Kirkpatrick's 4-level evaluation model. Residents' reactions to the program (level 1 ) were mostly positive. Residents appreciated their ability to immediately integrate newly learned skills into their teaching roles. The first-year residents reported that the scribing activity facilitated the orientation process, and third-year residents agreed that first-year residents acclimated to the EMR more quickly.

Pre- and postintervention surveys evaluated changes in residents' attitudes toward teaching and perceptions of their teaching abilities (level 2). All residents felt more confident in their teaching skills and more comfortable giving feedback to other residents after participating in the RaT curriculum. Residents view peer feedback as more authentic than feedback from faculty, and perceive giving peer-to-peer feedback as an essential professional skill. ${ }^{15}$

The chart review evaluated the application of knowledge and skills gained during the program (level 3). Although there was no significant difference in evaluator ratings based on the quantitative chart review, anecdotal comments from reviewers noted that several 2016 charts had obvious omissions (eg, no documented physical exam) whereas such omissions were decreased in 2017. These comments were subjective, however, and would require a more rigorous qualitative analysis to assess their validity.

With the implementation of the RaT curriculum, first-year residents in 2017 saw $16 \%$ more patients during the orientation month than in 2016, indicating that the RaT curriculum had an impact on the larger context of the residency program (level 4), without compromising the quality of residents' education and orientation into the clinic. This increase may be the result of the near-peer mentorship provided by third-year residents during the scribing activity, which facilitated PGY-1 residents' familiarity with the clinic workflow and allowed them to develop questions, plans, and assessments more quickly and accurately than would have been possible by first-year residents working alone.

This study was limited by the small number of residents in the single family medicine residency program. The survey was developed by the authors and was not validated. The survey also relied on residents' subjective selfassessments of their attitudes and confidence toward teaching; an objective assessment of residents' teaching skills by an external evaluator would provide a more robust level 2 evaluation. It is also unclear whether increases in teaching comfort and confidence reported in the postintervention surveys were the result of the didactic sessions, the scribing activity, or both. Finally, each chart was reviewed by only one reviewer, therefore interrater reliability was not assessed.

Overall, this innovative RaT curriculum including a near-peer scribing activity was an effective way to improve residents' teaching skills and expedite the orientation of first-year residents in a safe learning environment.

\section{Tables and Figures}


Table 1: Pre- and Postintervention Survey Results From PGY-1 and PGY-3 Residents ${ }^{\mathrm{a}}$

\begin{tabular}{|c|c|c|c|c|c|c|}
\hline \multirow{2}{*}{ Survey Statement } & \multicolumn{2}{|c|}{$\begin{array}{l}\text { PGY1 } \\
(n=12)\end{array}$} & \multicolumn{2}{|c|}{$\begin{array}{l}\text { PGY3 } \\
(n=10)\end{array}$} & \multicolumn{2}{|c|}{$\begin{array}{c}\text { Total } \\
(n=22)\end{array}$} \\
\hline & Pre & Post & Pre & Post & Pre & Post \\
\hline I am confident in my teaching abilities. & 2.92 & 2.83 & 3.10 & 3.30 & 3.00 & 3.05 \\
\hline $\begin{array}{l}\text { I am aware of my strengths and weaknesses } \\
\text { as a teacher. }\end{array}$ & 2.83 & 3.08 & 3.00 & 3.20 & 2.91 & 3.14 \\
\hline $\begin{array}{l}\text { I am confident in my ability to assess a } \\
\text { learner's needs. }\end{array}$ & 2.33 & 2.92 & 2.70 & 3.20 & $2.50^{+}$ & $3.05^{\dagger}$ \\
\hline $\begin{array}{l}\text { I appreciate the importance of creating a } \\
\text { positive learning environment. }\end{array}$ & 3.75 & 3.75 & 3.70 & 3.50 & 3.73 & 3.64 \\
\hline I value active learning. & 3.75 & 3.75 & 3.60 & 3.70 & 3.68 & 3.73 \\
\hline $\begin{array}{l}\text { I feel comfortable asking questions of other } \\
\text { residents. }\end{array}$ & 3.50 & 3.58 & $3.30^{\dagger}$ & $3.80^{+}$ & 3.41 & 3.68 \\
\hline $\begin{array}{l}\text { I feel comfortable asking for feedback from } \\
\text { other residents. }\end{array}$ & 3.25 & 3.17 & 3.10 & 3.50 & 3.18 & 3.32 \\
\hline $\begin{array}{l}\text { I feel comfortable giving feedback to other } \\
\text { residents. }\end{array}$ & 2.17 & 2.75 & 3.00 & 3.40 & $2.55^{\dagger}$ & $3.05^{\dagger}$ \\
\hline $\begin{array}{l}\text { I am confident in my ability to assess the } \\
\text { effectiveness of my teaching. }\end{array}$ & 2.25 & 2.58 & 2.70 & 3.20 & $2.45^{\dagger}$ & $2.86^{\dagger}$ \\
\hline $\begin{array}{l}\text { I feel well-prepared to teach other residents } \\
\text { and/or medical students in the clinic. }\end{array}$ & 2.42 & 2.92 & 2.70 & 3.30 & $2.55^{\dagger}$ & $3.09^{\dagger}$ \\
\hline $\begin{array}{l}\text { I am interested in making medical education a } \\
\text { part of my future career. }\end{array}$ & 3.00 & 3.08 & 2.90 & 2.50 & 2.95 & 2.82 \\
\hline
\end{tabular}

a Mean scores reported.

† Statistically significant difference in median scores between pre- and postintervention survey $(P<.05)$.

\section{Acknowledgments}

The authors greatly appreciate the support of the AAFP Foundation, the Fort Wayne Medial Education Program (FWMEP) Family Medicine Center nursing and support staff, as well as the FWMEP faculty and residents in assisting with the successful completion of this research project.

Financial support: This research was funded by a grant from the American Academy of Family Physicians Foundation.

Presentations: This study was presented as a platform presentation at the Indiana Academy of Family Physicians Research Day on May 16, 2018 in Indianapolis, IN, and at the American Academy of Family Physicians National Conference on August 2, 2018 in Kansas City, MO.

\section{Corresponding Author}

Leslie A. Hoffman, PhD

Indiana University School of Medicine-Fort Wayne, 2101 E Coliseum Blvd, Fort Wayne, IN 46805. 260-481-0510.

Fax: 260-481-6408.

lesahoff@iu.edu

\section{Author Affiliations}

Leslie A. Hoffman, PhD - Indiana University School of Medicine - Fort Wayne, IN

David T. Furman Jr, DO - Fort Wayne Medical Education Program, Ft Wayne, IN

Zachry Waterson, DO - Fort Wayne Medical Education Program, Ft Wayne, IN

Brian Henriksen, PhD - Fort Wayne Medical Education Program, Fort Wayne, IN

\section{References}


1. Busari JO, Prince KJAH, Scherpbier AJJA, Van Der Vleuten CPM, Essed GGM. How residents perceive their teaching role in the clinical setting: a qualitative study. Med Teach. 2002;24(1):57-61. https://doi.org/10.1080 /00034980120103496

2. Post RE, Quattlebaum RG, Benich JJ III. Residents-as-teachers curricula: a critical review. Acad Med. 2009;84(3):374-380. https://doi.org/10.1097/ACM.0b013e3181971ffe

3. Morrison EH, Rucker L, Boker JR, et al. The effect of a 13-hour curriculum to improve residents' teaching skills: a randomized trial. Ann Intern Med. 2004;141(4):257-263. https://doi.org/10.7326 /0003-4819-141-4-200408170-00005

4. Bazrafkan L, Raknejad S, Ghayoomi MA, et al. Effectiveness of residents as teachers, researchers and role models: a unique program at SUMS. J Med Educ. 2015;14(2):45-51.

5. Al Achkar M, Davies MK, Busha ME, Oh RC. Resident-as-teacher in family medicine: a CERA survey. Fam Med. 2015;47(6):452-458.

6. Morrison EH, Friedland JA, Boker J, Rucker L, Hollingshead J, Murata P. Residents-as-teachers training in U.S. residency programs and offices of graduate medical education. Acad Med. 2001;76(10)(suppl):S1-

S4. https://doi.org/10.1097/00001888-200110001-00002

7. Wamsley MA, Julian KA, Wipf JE. A literature review of "resident-as-teacher" curricula: do teaching courses make a difference? J Gen Intern Med. 2004;19(5 Pt 2):574-581. https://doi.org/10.1111

/j.1525-1497.2004.30116.x

8. Ince-Cushman D, Rudkin T, Rosenberg E. Supervised near-peer clinical teaching in the ambulatory clinic: an exploratory study of family medicine residents' perspectives. Perspect Med Educ.

2015;4(1):8-13. https://doi.org/10.1007/s40037-015-0158-z

9. Lockspeiser TM, O'Sullivan P, Teherani A, Muller J. Understanding the experience of being taught by peers: the value of social and cognitive congruence. Adv Health Sci Educ Theory Pract.

2008;13(3):361-372. https://doi.org/10.1007/s10459-006-9049-8

10. Bulte C, Betts A, Garner K, Durning S. Student teaching: views of student near-peer teachers and learners. Med Teach. 2007;29(6):583-590. https://doi.org/10.1080/01421590701583824

11. Vygotsky LS. Mind in Society: The Development of Higher Psychological Processes. Cambridge, MA: Harvard University Press; 1978.

12. Frye AW, Hemmer PA. Program evaluation models and related theories: AMEE guide no. 67. Med Teach. 2012;34(5):e288-e299. https://doi.org/10.3109/0142159X.2012.668637

13. Pettit J. Resident Teaching Skills Manual, Rev. 9. 2016. https://www.researchgate.net/publication /304011487_Resident_Teaching_Skills_Manual_Rev_9. Accessed February 27, 2018.

14. Neher JO, Gordon KC, Meyer B, Stevens N. A five-step “microskills” model of clinical teaching. J Am Board Fam Pract. 1992;5(4):419-424.

15. de la Cruz MS, Kopec MT, Wimsatt LA. Resident perceptions of giving and receiving peer-to-peer feedback. $J$ Grad Med Educ. 2015;7(2):208-213. https://doi.org/10.4300/JGME-D-14-00388.1

Copyright (C) 2019 by the Society of Teachers of Family Medicine 